\title{
Application of Active Psychology in Mental Health Education
}

\author{
LIN Jieli*, YAN Nong-qiu \\ Foshan University, Foshan City, Guangdong Province, 528000, China \\ lishalin@163.com \\ "Corresponding author
}

Keywords: active psychology; mental health education; communication

\begin{abstract}
The special policy of mental health education has been promulgated continuously by the state, which shows that the attention and importance to mental health education are increasing year by year. However, psychological individuals need to establish their inner emotional and psychological concerns, establish a new concept of active psychology, and propose three active contents of actively feeling inner emotions, actively seeking counselling, and actively cooperating with psychotherapy. Psychological individuals also need to improve their psychological self-healing ability. At the same time, students, parents, and teachers themselves improve their understanding of mental health education, and demonstrate effective communication through cases to achieve the goal of guiding life through correct psychological state.
\end{abstract}

\section{Introduction}

A series of mental health education policies formulated by the state are developing in stages, which shows that the attention paid to them is increasing year by year, and the proportion of mental health education in education has increased significantly[1]. The introduction of the special policy on mental health education is enough to show the great attention of the state, society and schools to mental health education. Improving the psychological quality of students is the ultimate goal of mental health education. It is necessary to do the work of psychological crisis intervention, of psychological counseling for the students who have the psychological barriers and problems, and of the mental health education for the whole students. For example, the various courses are combined with the psychological science[2] in the classroom. The psychological counseling is timely, effective, and high-quality services to optimize the psychological quality of students, so as to prevent and reduce psychological problems and psychological barriers and the unexpected events. Under the environment of sufficient attention and vigorous publicity, students are paying more and more attention to their psychological quality. They changes from passive notification to active seeking. However, the students themselves, the parents of the students and the teachers still have different understandings. Although the mental health education becomes be very important in superficial view for them, their inward hearts are not attached to the same attention and they lack the cognitive system of the mental health education. This paper proposes a new concept of active psychology, with a view of improving students, parents, and teachers' own understanding of mental health education, and demonstrating effective communication through cases to achieve the goal of guiding life through correct psychological state.

\section{Policy development process of attaching importance to mental health education}

Mental health education should be based on education, focus on popularization, prevention, and multi-participation as a guide[3].Mental health education in the modern scientific sense originated from psychological counseling[1], which was firstly developed in the United States[4], Europe and other regions. Compared with foreign countries, China's mental health education started late[5]. In 
1983, Lin Chongde[6] proposed the concept of mental health and advocated mental health education for the first time. The first formal proposal of the concept of mental health education was published in the rule of Several Opinions of the Central Committee of the Communist Party of China on Further Strengthening and Improving School Moral Education on August 1994, which emphasized the need for mental health education and guidance for students of different ages to help them improve their psychological quality. In July 2017, the ministry of education included the mental health education subject in the primary and secondary school teacher qualification examination. In August 2017, the guidelines for moral education in primary and secondary schools promulgated by the ministry of education clearly incorporated mental health education into the scope of moral education in primary and secondary schools. In addition, colleges and universities have set up departmental mental health education counseling center departments and secondary psychological counseling stations, and provide psychological counseling to the whole school students[7]. The course such as the guidance for college students' mental health is set in the first year for college students. It can be seen that the state, society, and schools have given enough attention to the mental health education of students.

\section{Psychological individuals' understanding of mental health education}

Psychological individuals have begun to pay attention to mental health education from the rationality of mind because of external policy requirements. Especially after the occurrence of many bad behaviors caused by psychological problems in social and campus, they are more aware of the importance of cultivating psychological quality. However, in order to play better the role of mental health education, psychological individuals also need to pay attention from their hearts. The change of the human heart is faster and more complicated than all things and the structure of personality is divided into three parts: id, ego and superego. The concept of human self-consciousness is gradually formed in the process of growth, starting from the concept of self, to self-evaluation, and finally to the category of self-ideally. During the period, people's psychological activities could be enriched, and the psychological structure tends to be stable. When the body is unwell, the first thing that comes to mind is to find a doctor, because you have been taught since childhood. When psychological discomfort occurs, it is not encouraged and it is hidden unless a certain degree of abnormal behavior is caused. Because the environment of growth does not attract enough attention to the invisible psychological attention. Physical health is easy to see and is acutely perceived. However, mental health is invisible and easily overlooked. It is often discovered through behavioral manifestations, because all effects are sent out by the heart. More and more people admit that people's psychology needs health as well as the body. People's health standards include both the physical and mental health.

\section{The new concept of active psychology}

The human body is born with an immune system that is used to resist all external invaders that are harmful to the body and to restore damaged parts. It belongs to its own healing system. The human psychology also has the ability to heal itself similar to the case that the body has a healing system, and this part of the ability is called active psychology. It contains four contents: facing psychological problems by utilizing the psychological self-healing ability, resisting psychological problems by mobilizing the self-healing ability, preventing psychological problems by improving the self-healing ability and overcoming psychological problems by believing the psychological self-healing ability. The optimal way to determine mental health by active psychology consists of three aspects, as shown in Figure 1. Maintaining a healthy mind requires constant supply of mentally nutritious food. Invisible nutritious food is the awareness of mentality, requiring psychological individuals to adjust their cognition; when the psychological imbalance occurs, you 
can adjust to the normal state by relying on your own healing ability. If the result could not be realized by your ability, you could go to the second way-consult. It is recommended to communicate with friends and relatives, or get targeted counseling from the counselor to ease your mind and restore your health. If the state of mental state cannot be adjusted through simple counseling, the third way is treatment. It is recommended to receive special training and physiotherapy programs given by mental health counseling experts, and even accept effective treatment plans from relevant doctors to achieve the purpose of controlling psychological symptoms. Obviously, maintaining mental health needs to change the incorrect ideas held by psychological counseling, and the relative person should be brave to face psychological counseling, and face psychological treatment correctly. To maintain mental health, we need to achieve "three actively": actively feel psychological changes in emotions, actively consult experts on counseling skills, and actively cooperate with professional treatment programs. Meanwhile, it is necessary to maintain effective communication with people, establish trust with consultants, and actively share the mental process of recovering psychological symptoms, thereby improving psychological quality. In short, the formation of active to pay attention to the psychological consciousness, active to seek help, and correctly face the treatment process of special professional personnel, which is the specific thinking of active psychology.

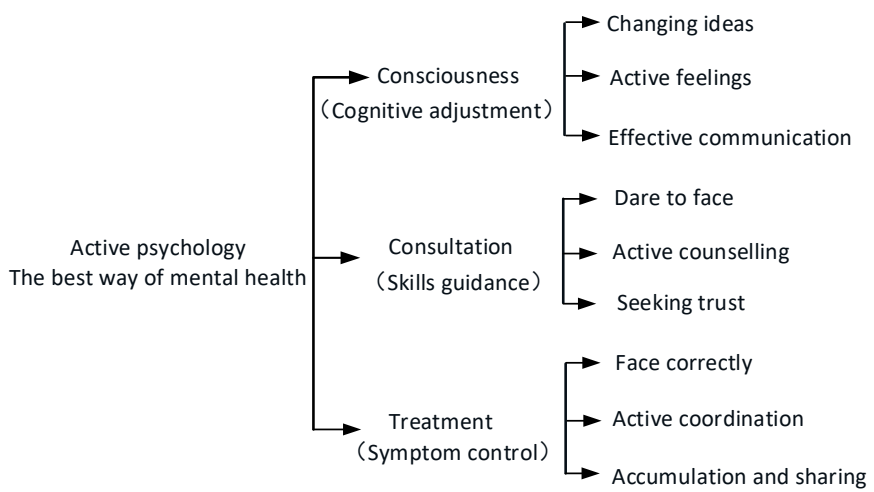

Figure 1 . The optimal approach to mental health brought about by active psychology

\section{The case of applying active psychology}

A psychological individual with active psychological consciousness can more accurately judge the development of the situation and easily restore the truth. Student A in a middle school class usually likes to take the things of classmates and the public goods of the class for playing. If he made a mess of them after playing, he was unwilling to pay compensation. Instead, he thought that the owner was stingy and argued that things were supposed to be broken. When there was a conflict with the friction between him and the classmates, he often excitedly screamed. Therefore, most of his classmates are not willing to play with him, and even avoid him. But student B has a good relationship with him, because student B admires his method of designing games. Student B is introverted, obeys the law, gets along well with classmates, and has good discipline. Student $\mathrm{C}$ is cheerful and naughty. He likes to do some pranks, but he is very reconciled when he has a conflict with his classmates. One day, student $\mathrm{C}$ came back from the toilet and found that the sleeves of his jacket on the desk was deliberately wet, and only students A and B were doing homework in the classroom at this time. Therefore, student $\mathrm{C}$ immediately suspected that it was a mischief done by student A and reported to the class teacher. The class teacher asked the student A, "Why did you sprinkle water?" Student A replied without hesitation, "It was not me. It was sprinkled by student B." Seeing that student A did not recognize, the teacher and student $C$ were very angry. The teacher pointed at his pot which was next to the student A's seat, and said, "This is an evidence. Why did you do your good friend B an injustice?" At this time, the classmates went into the classroom, and someone said, "I know student A often plays with water and sprinkle water using his pot on the 
ground. It must be done by him." The teacher said, "Many students say that it is you who sprinkled, why didn't you admit it?" But the psychological teacher who has a different perspective view on the problem realized that there was something wrong with this case. He invited students A and C to the counseling room and asked them to describe what they saw and thought. Student A said, "When student C left the classroom, student B asked me to borrow my pot. I gave it to him. But I saw him use it to sprinkle water on the clothes of student C. After he gave it to me, student C came back." Student C said, "Although I did not see student A sprinkling water, I am sure he did because I saw him laughing with student B. I know student B may not sprinkle water on my clothes." The psychology teacher took an active feeling to both students A and C, realizing that one of students A and $\mathrm{C}$ could lie. The reason that every classmate thinks student A did is based on the evaluation system of the individual's performance according to the daily performance of student $\mathrm{A}$. But the psychology teacher did not think so. He knew that the human heart had a sudden thought in addition to the formed heart. He talked with student B alone, asked him to tell him what happened. Student B said, "I saw C going out. Then I went to the toilet and saw other students running into the classroom. When I came back, I saw student C shouting 'who did it?'. I thought someone did, anyway, not student A." The psychology teacher realized that B was lying. He made effective communication of active psychology with $\mathrm{B}$. At last student $\mathrm{B}$ recognized that he sprinkled because last week student $C$ had accidentally bumped into student B and made B hurt. Therefore, when student B saw student $C$ went out, there was a revenge idea to wet his clothes. The whole class would not believe that student B sprinkles water. When the class teacher heard the truth, he could not believe the facts because he knew the students $\mathrm{A}, \mathrm{B}$, and $\mathrm{C}$ better. He thought that student $\mathrm{B}$ admitted his misdeed in order to help student A. In the beginning, student B lied to every one because $\mathrm{B}$ was afraid of the teacher's criticism and the classmates' eyes. The class teacher chose to believe the words from both students $\mathrm{B}$ and $\mathrm{C}$ according to their daily performance. However, the psychological teacher played an active psychological role, so that student B finally told the truth. The result shows the difference between active psychology and un-active psychology.

\section{Conclusions}

The application of active psychology in mental health education embodies that the active psychology makes students obtain the depth of their sensibility in the experience, think in the sentiment, and experience in the thinking. Students can open their minds and adjust their mental state through active communication and effective communication between teachers and students. By restoring the truth, it shows that people should not look at people from a single point of view, should not evaluate people from their past, should respect each other's psychology and accept the correct psychological guidance.

\section{References}

[1] Yu Guoliang, Chen Yunting. Historical process analysis and enlightenment of China's mental health education policy [J]. Journal of the Chinese Society of Education, 2018 (10): 40-48.

[2] Zhang Lianyun. Current situation and Countermeasures of mental health education in primary and secondary schools [J]. Ability and Wisdom, 2018 (18): 34-35.

[3] Yao Jianglin, Zhang Yanhua, Cui Fenghua. Causes of psychological problems of college students in agricultural colleges and Countermeasures [J]. Higher Agricultural Education, 2010, 9 (9): 93-95.

[4] Wang Dinghua. American Basic Education: Observation and Research [M]. Beijing: People's Education Press, 2016:237.

[5] Yu Guoliang. Social Transition: Mental Health Education Report [M]. Beijing: Beijing Normal 
University Press, 2017:39-40.

[6] Lin Chongde. Middle School Students Psychology [M]. Beijing: Beijing Education Press, 1983:290.

[7] Yan Nongqiu. New Edition of Mental Health Guidance for College Students [M]. Beijing: China Light Industry Press, 2016. 